\title{
Factors influencing contraceptive choice: study focused on Czech men
}

\author{
Adela Capova* \\ Faculty of Health and Social Studies, University of South Bohemia, Ceske Budejovice, Czech Republic \\ Received: 2 September 2014 \\ Accepted: 19 September 2014 \\ *Correspondence: \\ Dr. Adela Capova, \\ E-mail: ada.kubi@seznam.cz \\ Copyright: (C) the author(s), publisher and licensee Medip Academy. This is an open-access article distributed under \\ the terms of the Creative Commons Attribution Non-Commercial License, which permits unrestricted non-commercial \\ use, distribution, and reproduction in any medium, provided the original work is properly cited.
}

\begin{abstract}
Background: The man's participation in family planning appears as a suitable means for improvement of relationships between couples and their children. Gender sensitive breeding is a good way for supporting responsibility in family planning between man and woman and leads them in equal negotiation in questions of parenting. The purpose of research is to monitor contraception strategies and conditions affecting the timing of parenthood.

Methods: Data were collected by interviews with 170 Czech men aged between 25 and 50. Grounded theory approach was used to generate new related theoretical ideas.

Results: The present young men leave the decision rather up to women. A number of young men enter a relationship assuming automatically that their partner uses hormonal contraception. Family planning decision-making is influenced by personal values as well as structural factors. Strong social pressure determining the ideal form of material and psycho-social background for offspring confronts current generation with very demanding decisionmaking on parenthood timing.

Conclusions: In men's opinion, the setting of conditions for the beginning of reproduction should be the result of negotiation within the couple. Although men speak of the need to negotiate, the responsibility and practical decisionmaking is left up mainly to women.
\end{abstract}

Keywords: Fatherhood, Family planning, Contraception, Qualitative research

\section{INTRODUCTION}

Although both men and women make important contributions to bringing children into life, studies on fertility and family planning were focused overwhelmingly on women (Greene \& Biddlecom, 2000).

Women are far more interested in reproduction and more closely involved in every aspect of it. Because it is the woman's body that carries and nourishes a fetus. Men's involvement in reproduction is increasingly recognized as important not just only of female well-being but also on the needs of fathers themselves (Sheldon, 2006).

Despite the reality that women and men must both play their respective roles in making babies, men's thoughts and feeling about sex, pregnancy, abortion, babies and fatherhood have often been ignored or overshadowed by women's voices (Marsiglio \& Hutchinson, 2004).

One of the most influential images of fatherhood for many centuries has been the patriarch what literally means father and ruler. In hands of medieval church and state, the image of the patriarch became the over-arching image of patriarchy in both heaven and earth, with one layer of fatherhood resting upon another. God is the father and ruler of heaven and earth, the king is the father and ruler of his people, the priest is the father of his flock and the man is the father and head of his family (McKeown, 1996). 
Around the time of industrialization primary focus shifts from moral membership to breadwinning and economic support of the family (Lamb, 2004). The patriarch became the provider and the roles of father and mother became increasingly segregated, even polarised. Men were seen as naturally de-skilled in the art of child rearing and care giving (McKeown, 1996).

The topic of fatherhood has begun to solve itself in association with feminist movement in the seventies in Western Europe. During the seventies the model of "new fatherhood" has appeared and it is starting to promote the opinion that fathers are able to be active in children care and that this care is beneficial for fathers and their children as well (Evans \& Fogarty, 1999).

Another perspective influences reproductive responsibilities. Approval of the oral contraceptive pill changed the link between sexuality and contraception and altered the balance of male-female involvement in contraceptive use. The realm of contraception became increasingly a female arena. Men were distanced from method choice and use. Some men have undoubtedly been glad to leave this responsibility to women (Nelson, 2000).

There is a little doubt that our society would be decidedly different if more men were mindful of their ability to procreate and genuinely concerned, prior to conception, about how a new baby and child's mother might fare in the society. We should foster men's awareness of their own gift to create new human life while having them recognize that this ability can influence others' lives either positively or negatively as well. The ultimate challenge of this fact is twofold. First is to help young men at an early age, ideally before they become sexually active, to achieve and sustain a deeper self-awareness of their power to create new life. Second, encourage men to be attentive to the best interest of others, as well as their own, as they contemplate their readiness to become biological and social fathers (Marsiglio \& Hutchinson, 2004).

Practice shows when men are involved in reproductive health decisions and concerned about equity, men and women are more likely to communicate with each other, make joint decisions about contraceptive use, discuss how many children they would like to have, and be actively involved in child rearing and domestic chores (Engenderhealth, 2008).

We are often told that reproduction is women's business. They are far more interested in reproduction and more closely involved in every aspect of it. It is the woman's body that carries and nourishes a foetus. There is a slowly changing perception that men's influence in pregnancy and childbirth (and) has revealed men's involvement in reproduction. In US studies male parents have been shown as important in affecting the timing of first pregnancy. Men's involvement in reproduction is increasingly recognized as important not just only for female well-being, with attention also focused on the needs of fathers themselves (Sheldon, 2006).

While much of the research is focused on men who have already become fathers, the topic of potential fatherhood has not yet met with appropriate attention (Marsiglio \& Hutchinson, \& Cohan, 2000).

An expanding use of modern contraception allows regulate not only the number and also timing of child. It should be the result of negotiation about parenthood within the couple. For understanding the reproductive behaviour of childlessness seems to be important explain the processes of ways how partners negotiate about parenting. In the Czech society were identified the factors influencing ratio of childlessness or prolongation of childlessness (Haskova, 2010).

Contraceptive use is related to many factors (sexuality, age, parity, accessibility to family planning facilities, social policy, moral, cultural and religious convictions). Interaction between these factors is complex and it is difficult to evaluate single factors (Lindh, 2011).

The goal of this qualitative research was to map the factors that significantly influence the choice of contraceptive methods in Czech men in their reproductive age. It can be expected that with the extension of exclusively female method of hormonal contraception men are excluded from the practical parenthood planning and their role within the choice of contraception method is rather passive.

\section{METHODS}

Within the survey focused on the monitoring of men's attitudes towards parenthood planning. A part of the research question focused on the choice of contraceptive method. The term 'parenthood planning' has been defined according to the World Health Organization as a collection of measures which allow individuals and couples to anticipate and attain their desired number of children and the spacing and timing of their births. It is achieved through use of contraceptive methods and the treatment of involuntary infertility (WHO, 2014).

From the autumn of 2008 to the spring of 2011170 men aged 25 to 50 were asked. Information was obtained through semi-structured interviews. Interviews were conducted by trained students at the Faculty of Health and Social studies on the basis of their own choice. The contacts with the research participants were established on the basis of the interviewers' personal acquaintance.

The chosen procedure assumed that semi-structured interviews with men on a topic they generally do not like to talk about openly, a greater success is assumed if the respondent knows the researcher personally or the 
meeting with the researcher is organized by a close person (Burgess, 1997).

An important indicator for the selection of men was their age and consent to carry out an interview. In all respondents we know their age, marital status, childlessness/parental experience. The level of education and employment is not known to us in all respondents. According to the figures that have been available to use we can say that the sample is diverse with varied educational and economic and fertility experience backgrounds.

Out of the total 170 interviewees 73 (43\%) were childless, aged 25 to 30 . There were 36 (21\%) interviewees with a parental experience aged 31-40, there were 34 childless men (20\%) aged 31 and more. The least numerous group was made up of men with a parenting experience, aged 41 to 50, they were 27 (16\%).

Another surveyed quota sign in respondents was the presence/absence of affiliate heterosexual relationship. $185(93 \%)$ respondents out of total stated that they have currently had a partnership, which they have thought is a promising one and 12 men (7\%) stated they have been without a stable partnership. Even men who have stated an absence of a stable partnership had had a previous experience with a long-term relationship.

Data were analyzed by using grounded theory method to generate new related theoretical ideas. In the initial phases of data analysis an Atlas.ti. software for qualitative data analysis was used.

\section{RESULTS}

Contraceptive methods are tools that enable family planning. The results of this survey may be analyzed on two levels. Although the survey has been oriented qualitatively, it is possible to quantify the first part of the results. According to the respondents' statements it is possible to represent the popularity of chosen contraceptive method in numbers. The most popular method was hormonal contraception (67\%). $14 \%$ of respondents pointed to a combination of different methods. The choice was followed by a condom $(9 \%)$ and coitus interruptus (7\%). Intrauterine device and counting fertile and infertile days methods mentioned as main contraceptive methods had just scant representation in the respondents' statements.

Other contraceptive methods were only mentioned by the respondents just as a part of a list of methods that they have known, not used. Sometimes they pondered upon male vasectomy, which was, however, strictly refused.

The findings of a qualitative nature focused on the analysis of factors influencing the choice of a specific method as well as influencing the man's role in the use of a contraceptive method. The obstruction to conception is becoming in the light of context a very variable contraceptive strategy.

The choice of a contraceptive method has in men's testimonies reflected the length of a partnership. Random relationships have been linked to three common signs. Men have relied more on themselves. A random relationship has required protection - the use of a condom. With unknown women men would protect themselves not only from an unwanted pregnancy but especially from sexually transmitted diseases. Not always and not all would act responsively in such a relationship. If the respondents relied on their sexual partner, at least they checked that a form of obstruction to pregnancy would be used. Testimonies saying that partners would not deal with the question of obstructions to pregnancy at all if a random sexual intercourse occurred emerged less often.

According to the testimonies the choice of contraceptive method in a long-term relationship should be the result of an agreement with a partner. The respondents have repeatedly mentioned that the use of hormonal contraception preceded the use of condoms. The change of contraceptive strategy may be related to the increase of trust towards the partner, and not only in the sense of responsibility for the use of tablets, but also in the sense of partner loyalty.

The degree of personal responsibility in men's attitudes is becoming a significant topic in the choice of contraceptive methods. In the choice of hormonal contraception the man's manifestation of personal responsibility for obstruction to pregnancy is much more complicated than in other methods of obstruction to conception. This method of obstruction to conception is exclusively female and men participate in many different ways in its use.

Although men cannot use hormonal contraception they would like to participate in its choice, for instance. The respondents saw an important role in the financial contribution to hormonal contraception. A number of men however admitted that an agreement about hormonal contraception went completely aside if their partner decided for its use, or if she had been using it already before the start of their relationship. Although importance has been attached to the agreement with the partner, men admitted that the practical choice and use of contraceptive method is the woman's responsibility.

The popularity of hormonal contraception use has been distinct in the testimonies. Hormonal contraception brings, compared to other methods, advantages in the sense of reduced uncertainty about unwanted pregnancy, a better enjoyment of the sexual intercourse itself, which brings men the carelessness in its use. Other methods of obstruction to conception than hormonal contraception have not been as popular with the respondents. They 
connected the use of other methods with discomfort, uncertainty, and depletion.

In addition to the benefits of hormonal contraception use, references to the disadvantages of its use also appeared in the testimonies. Most frequently the respondents connected them to the undesirable side effects and fertility problems. Sometimes the respondents' partners wanted to use hormonal contraception but some contraindications, such as venous diseases or liver diseases prevented her from it. Another reason for not using hormonal contraception as a contraceptive method has been that the use of hormones has not been the partners' life philosophy.

If we focus on the analysis of responses relating to other contraceptive methods than hormonal contraception then the respondents commented mostly on the condoms, coitus interruptus, intrauterine device and counting of fertile and infertile days. Men used the condom voluntarily in their initial relationships as a protection from conception as well as from STD diseases. As it has been said above, most couples changed to another type of contraception during some time. Only a small percentage of men used a condom within a long-term relationship. A coitus interruptus method was chosen voluntarily by some men as a presentation of their skills. It has been mentioned rather as an additional method together with another, main one. From the total of respondents there were only two men who stated that their partners used an intrauterine device. The choice of counting of fertile and infertile days method as the only method used corresponded with religion and was used rather as an additional method to another, main one.

The conducted analysis of chosen contraceptive methods with regards to the age of respondents pointed to intergenerational differences. The choice of contraceptive methods in men who are now in their mean age, has been influenced by the former social norms. In the beginning of the 90's men entered their productive life in a time when the question of obstruction to conception was a taboo. Except for condoms and coitus interruptus there was practically no other contraceptive method available. Except the perception of social norms, the personal maturity of men when entering parenthood planning seems to be the key topic in intergenerational analysis. Enough information and available contraceptive methods make the shift of childbirth easier for the young generation, until they reach an age when they are able and willing to take over the responsibility for childcare.

\section{DISCUSSION}

People have gained several ways of regulating the arrival of parenthood. Especially for women the invention of hormonal contraception is revolutionary. It has freed them from the man's superiority over parenthood planning. It is the availability of hormonal contraceptives, which has enabled women to become independent in postmodern society. Undoubtedly the availability of contraceptive methods is a great advantage. However, on the other hand, we cannot neglect other respects that are brought by these possibilities (Nelson, 2000).

Parenthood is often connected to women, either in the phase of potential parenthood, pregnancy or the children's upbringing. The ancient male power to conquer a woman through motherhood is nowadays tilted into another extreme where it is the women who can decide about parenthood, without the man knowing, by dropping hormonal contraception.

As the most widely used contraceptive method is female hormonal contraception the man seems to be careless about its use. The man's role during parenthood planning is seen as passive, connected to the enjoyment of sexual intercourse, not as a pathway to potential parenthood (Sheldon, 2006).

This impression is only apparent, though, because the statements of our research prove that there are still enough men within the Czech population, who want to negotiate about contraceptives. As well as our thesis, other Czech research confirms that it is the life situation in which both partners find themselves that creates the important context of ways of negotiations and choice of contraceptive strategy (Salamounova \& Samanova, 2004).

Young couples usually automatically rely on the female partner using hormonal contraceptives. Because most of the current population up to 30 years of age studies, young people want to enjoy travelling and the material security is scant, the border between sexual intercourse itself and parenthood is usually divided. Parenthood becomes an experience, the question of a conscious choice (Beets, 2011). Hormonal contraception is also chosen by couples in long-term relationships, which is confirmed by a long-term research of sexual behaviour in the Czech population (Weiss \& Zverina, 2009). Having reached an agreement, men pass this possibility to women's hands, as they often believe in their greater reliability in regular use. Hormonal contraceptives, according to them, is a means of how to increase the woman's trust that there will be an unwanted pregnancy as well as it brings women a greater carelessness and pleasure connected with sexual intercourse. Hormonal contraceptives are available only for women; the actual use is therefore in her competence.

Most research has found that condom and dual method use become less consistent with more frequent sex and with increased relationship duration, whereas the use of only a hormonal method is more common in longer relationships and in relationships that involve more frequent sex (Frost \& Darroch 2008; Sayegh et al. 2006; Wilson \& Koo 2008).

Men take part in the choice of this contraceptive strategy in different ways. Even so we can find least men who do 
not care about the use of hormonal contraceptives at all, in our research sample, while others do see their role in financial contributions in the payment of contraception.

A research about male hormonal contraceptives has been conducted on a large group of volunteers in the past few years. At the moment this research is stopped (Page \& Amory \& Bremmer, 2008). The data obtained within this study unfortunately do not bring enough statements relating to hormonal contraceptives for men. We can only say that the willingness to choose this kind of contraceptive strategy meets only two types of opinion. Men refuse it as a means of health problems without discussion or they believe themselves not to be enough reliable to use a pill every day. On the other hand, though, there are some men who claim this way of contraceptive method to be a welcome means for dividing the responsibility in contraceptive strategies. Men's opinions suggest that male hormonal contraceptives might be another possible choice. For couples that would choose it, this would demand the same share of use responsibility from the man's side, as we encounter in female hormonal contraception (Heinemann, 2005).

Except hormonal pills there are other ways of male contraception methods protection against an unwanted pregnancy. Users emphasised taking responsibility as men for family planning and protecting their female partners from possible adverse effect of contraception (Bulut, 1997). Although modern methods requiring male participation are less common, men mostly use condoms and withdrawal. Male condom used is most common in Europe; it is around 25 per cent of use (United Nations, 2013). A higher risk of failure of withdrawal or reduced sexual pleasure associated with using condom caused that couples prefer hormonal contraception. The possibility of almost easy postponing of parenthood brings the feeling of comfort and enjoyment of sexual life. Especially young women enter relationships with an already established use of hormonal contraception.

In a long-term relationship other contraceptive strategies are used less often and always preceded by an agreement of both partners. The most common reasons for not using hormonal contraceptives are possible health problems or fear of adverse effects in women. In such a case then there is the choice of male barrier contraception, such as condoms or interrupted sexual intercourse. Men in our research group consider the use of condoms to be important especially in random sexual intercourse, where they serve not only as a protection against an unwanted pregnancy, but also as a protection against sexually transmitted infections (STI's), on which we agree again with the findings of Weiss and Zverina (2009).

In spite of the mentioned advantages of hormonal contraceptives, such as enjoyment of sexual activity or family planning postponed to the most appropriate time, couples come into conflict with the disadvantages, such as a one-sided decision about the child by the woman only, transmission of STI as well as fears of a bad influence on reproductive health. The advantages of hormonal contraceptives are confronted with their disadvantages, which might cause a significant overlap into the relationship layer.

\section{CONCLUSION}

In the developing states there are still millions of people who do not have an access to effective contraceptive methods. Not even in the states where contraception is available is it always possible to separate the sexual act from reproduction and unplanned and unwanted children are born. Men interviewed within the survey did not have to calculate with the wish of available contraceptive method.

The possibility of separating sexual life from procreation has become an inherent part of their partner lives. The result analysis, focused on the choice of contraceptive method can take place on two levels. The first level is focused on the evaluation of popularity of contraceptive methods. A certain method of obstruction to conception is only a tool, which does not tell us, on its own, anything about the relationships within which the method has been chosen. The second level submits the analysis of factors that influence the choice of method.

Hormonal contraception has been mentioned in the research file as the most often used contraceptive method. Hormonal contraception has been popular in childless respondents, in young fathers, as well as men in their mean age. In respondents up to the age of 30 the answer that the partner has been already using hormonal contraception before entering the current relationship and she has continued using it, therefore the respondent avoided deciding, has occurred more often. From the respondents' points of view the use of hormonal contraception has been most often refused due to negative side effects of varying character.

Most often due to health state, side effects or its use has not responded to the life philosophy of the respondents. In short-term and random relationships a condom has been the most preferred as a protection against sexually transmitted diseases. A condom has been considered to be necessary in the first phases of a relationship, but if men were able to, they retreated from its use. In a lasting relationship a minimum of respondents used it regularly. Other forms of contraceptive methods have reached a less rate of choice in the testimonies.

In relation to the qualitative results of the survey, we can say that the main measure for contraceptive strategy choice is the perspective of a partner relationship. Together with the lengthening of a partnership the rate of trust was growing between the partners in the sense of mutual partner loyalty. Within the choice of contraceptive strategy the rate of responsibility with which the sexual partners enter plays the most important role. 
As a relationship progresses, partners likely know more about each other and may also assume exclusivity, and therefore may find it less important to use condoms because these relationships are believed to be of lower STI risk. These more committed relationships may then choose to rely only on a hormonal method instead of a condom or dual method because concern turns to prevention of pregnancy rather than STIs (Kusunoki \& Upchurch, 2011).

Sexual intercourse is an instinctive issue intended for offspring procreation. As a side, but preferred effect, sexual intercourse has a recreational purpose, connected to an enjoyment of sexual activity (experienced together or individually).

Thanks to the spread of hormonal contraception method the responsibility for keeping sexual life at the level of recreation is taken over especially by the woman. For both partners then sexual life brings obvious benefits, such as comfort, certainty. Men perceive their level of involvement within the choice of hormonal contraception in different ways. Mostly they support the choice financially. The situation of many men has been facilitated by the use of hormonal contraception. For a number of them it is more comfortable that the responsibility has been taken over by their partner, and this is without the regard to the interviewed men's age.

To make the conclusion that parenthood planning is the women's responsibility would be, however, simplistic. The responsibility does not rest even in the choice of contraceptive method, as in its use. Thanks to hormonal contraception the woman carries more responsibility within the part of recreational and procreation purpose of sexual life.

Funding: No funding sources Conflict of interest: None declared

Ethical approval: The study was approved by the institutional ethics committee

\section{REFERENCES}

1. Beets G, Schippers J, Velde E, Te R. Late fertility and its consequences. In: Beets G, Schippers J, Velde E, Te R, eds. The Future of Motherhood in Western Societies. Netherlands: Springer Science + Business Media B.V.; 2011.

2. Burgess A. Fatherhood reclaimed. In: Burgess A, eds. The Making of Modern Fatherhood. Vermilion: University of Virginia; 1997.

3. Bulut A, Filippi V, Marshall T, Nalbant H, Yolsal N, Graham W. Contraceptive choice and reproductive morbidity in Istanbul. Stud Fam Plann. 1997;28(1):35-48.

4. Engenderhealth. Introduction to men reproduction health services, 2008. Available at: http://www.engenderhealth.org/pubs/gender/mensrh-curriculum.php.
5. Evans GD, Fogarty, K. (2009). The common roles of fathers: the five Ps, 2009. Available at: http://edis.ifas.ufl.edu/pdffiles/HE/HE14000.pdf.

6. Greene ME, Biddlecom AE. Absent and problematic men: demographic accounts of male reproductive roles. Popul Dev Rev. 2000;26(1):81-115.

7. Frost JJ, Darroch JE. Factors associated with contraceptive choice and inconsistent method use. Persp Sex Reprod Health. 2008;40:94-104.

8. Haskova H. Fenomen bezdetnosti. In: Haskova H, eds. The Phenomenon of Childlessness. Praha: Slon; 2009.

9. Heinemann K, Saad F, Wiesemes M, White S, Heinemann L. Attitudes toward male fertility control: results of a multinational survey on four continents. Hum Reprod. 2005;20(2):549-56.

10. Kusunoki Y, Upchurch DM. Contraceptive method choice among youth in the United States: the importance of relationship context. Demography. 2011;48(4):1451-72.

11. Lamb ME. The role of the Father in Child Development. In: Lamb ME, eds. A Book. 4th ed. Hoboken: John Wiley \& Sons; 2004.

12. Lindh I. Factors influencing women's choice of contraception. In: Lindh I, eds. A Book. Sweden: University of Gothenburg; 2011: 1-86.

13. Marsiglio W, Hutchinson S. Sex, men, and babies. In: Marsiglio W, Hutchinson S, eds. Stories of Awareness and Responsibility. New York: New York University Press; 2004.

14. Marsiglio W, Hutchinson S, Cohan M. Envisioning fatherhood: a social psychological perspective of young men without kids. Fam Relat. 2000;49(2):13342.

15. McKeown K, Ferguson H, Rooney D. Changing fathers? In: McKeown K, Ferguson H, Rooney D, eds. Fatherhood and Family Life in Modern Ireland. Cork: The Collins Press; 1998.

16. Nelson AL. Whose pill is it, anyway? Fam Plann Persp. 2000;32(2):89-90.

17. Page T, Amory JK, Bremmer WJ. Advances in male contraception. Endocr Rev. 2008;29(4):465-93.

18. Salamounova P, Samanova G. Reprodukcni zamery mladych lidi. Nase Spolecnost. 2004;2(1):8-11.

19. Sayegh MA, Fortenberry JD, Shew M, Orr DP. The developmental association of relationship quality, hormonal contraceptive choice and condom non-use among adolescent women. J Adolesc Health. 2006;39:388-95.

20. Sheldon S. Reproductive choice: men's freedom and women's responsibility? Pedain A, Spencer J, eds. Freedom and Responsibility in Reproductive Choice. 1st ed. London: Hart; 2006: 175-195.

21. United Nations. Trends in contraceptive methods used worldwide, 2013. Available at: http://www.un.org/en/development/desa/population/ publications/pdf/popfacts/popfacts_2013-9.pdf.

22. Weiss P, Zverina, J. Sexualni chovani ceske populace/sexual behavior of the Czech population. Urologie Pro Praxi. 2009;10(3):160-3. 
23. Wilson EK, Koo HP. Associations between lowincome women's relationship characteristics and their contraceptive use. Persp Sex Reprod Health. 2008;40:171-9.
24. World health Organization. Family planning, 2014. Available http://www.who.int/topics/family_planning/en/.

DOI: $10.5455 / 2320-1770$. ijrcog20141202

Cite this article as: Capova A. Factors influencing contraceptive choice: study focused on Czech men. Int J Reprod Contracept Obstet Gynecol 2014;3:880-6. 